\title{
FEASIBILITY OF UTILIZING A ROTATING FLUIDIZED BED FOR THE REMOVAL OF SULFUR FROM HOT GASES
}

PROGRESS REPORT

April 1980

Prepared by:

C.H. Waide and H.P. SeRRY

For the

MORGANTOWN ENERGY TECHNOLOGY CENTER (Field Mgr.) OFFICE OF COAL UTILIZATION DEPARTMENT OF ENERGY

DEPARTMENT OF ENERGY AND ENVIRONMENT

BROOKHAVEN NATIONAL LABORATORY UPTON, NEW YORK 11973 


\section{DISCLAIMER}

This report was prepared as an account of work sponsored by an agency of the United States Government. Neither the United States Government nor any agency Thereof, nor any of their employees, makes any warranty, express or implied, or assumes any legal liability or responsibility for the accuracy, completeness, or usefulness of any information, apparatus, product, or process disclosed, or represents that its use would not infringe privately owned rights. Reference herein to any specific commercial product, process, or service by trade name, trademark, manufacturer, or otherwise does not necessarily constitute or imply its endorsement, recommendation, or favoring by the United States Government or any agency thereof. The views and opinions of authors expressed herein do not necessarily state or reflect those of the United States Government or any agency thereof. 


\section{DISCLAIMER}

Portions of this document may be illegible in electronic image products. Images are produced from the best available original document. 
BNL 51253

UC-90

(Coal Conversion and

Utilization - TIC-4500)

\section{FEASIBILITY OF UTILIZING A ROTATING FLUIDIZED BED \\ FOR THE REMOVAL OF SULFUR FROM HOT GASES}

PROGRESS REPORT

C.H. WaIDe and H.P. SerRY

April 1980

FOSSIL TECHNOLOGY GROUP

ENGINEERING DIVISION

DEPARTMENT OF ENERGY AND ENVIRONMENT

BROOKHAVEN NATIONAL LABORATORY

ASSOCIATED UNIVERSITIES, INC.

UNDER CONTRACT NO. DE-AC02-76CH00016 WITH THE

UNITED STATES DEPARTMENT OF ENERGY 


\section{DISCLAIMER}

This report was prepared as an account of work sponsored by an agency of the. United States Government. Neither the United States Government nor any agency thereof. uur any of their employees, nor any of their contractors, subcontractors, or thcir $\mathrm{cm}$ ployees, makes any warranty, express or implied, or assumes any legal liability or responsibility for the accuraç, completeness. or usefulness nf any information, appara. tus, product, or process disclosed, or represents that its use would not infringe privintuly uwurid riglits Reference herein to any epécific commcrcial product, prucess, on service by trade name, trademark, manufacturer, or otherwise, does not necessarily constitute or imply its endorsement, recommendation, or favoring by the United States Government or any agency, contractor or subcontractor thereof. The views and npinions of authors expressed herein do not necessarily statc or reflect those of the United States Government or any agency, contractor or subcontractor thereof.

Printed in the United States of America Available from

National Technical Information Service

U.S. Department of Commerce

5285 Port Royal Road

Springfield, VA 22161

Price: Printed Copy $\$ 5.00 ;$ Microfiche $\$ 3.50$ 


\section{ACKNOWLEDGMENTS}

The authors wish to express their appreciation to those who contributed significantly to the work described here. Currently this includes, Peggy Rosado, Chester Davis, Warren Johnson, Winfield Lewis, and, in the early stages of the effort, Frank Hill and Julius Milau. Thomas E. O'Hare contributed substantially in the conceptual stages of the project: 
This report presents the status of work directed toward determining the feasibility of a rotating fluidized bed (RFB) containing limestone for the removal of $\mathrm{SO}_{2}$ from hot combustion product gases. The work accomplished during the current fiscal year, through March, is described as are the results of the initial high temperature desulfurization experiments. The basis for adoption of the RFB approach and the potentlal benefits in terms of the initial results are considered to present a relatively comprehensive view of the project. The preliminary results indicate a significant reduction in residence time of gas in the bed compared to the conventional fluid bed combustor and an $\mathrm{SO}_{2}$ removal better than $99 \%$. The implications in terms of the size of an RFB gas desulfurizer for use in combustion power systems are discussed, 


\section{INTRODUCTION}

Scope of Report

This report describes the project activities during the current fiscal year through March 1980 and includes the initial results obtained in the operation of the rotating fluidized bed (RFB) with limestone sorbent. Results of a preliminary study done for BNL by the Stone \& Webster Engineering Corporation (SWEC) are also presented which indicate that the RFB is a feasible concept in the mechanical sense and which suggest additional paths for investigation. The present report couples the initial experimental results with the SWEC considerations to provide a basis for judging the potential, in terms of scale and capability, of the rotating fluidized-bed desulfurization. unit in hot gas cleanup service.

The RFB Option

The RFB provides an option for coal combustion systems by separating the desulfurization of hot combustion product gases from the combustion process itself. Fluid-bed combustors conventionally combine the two processes and, as a result, the rapid combustion process is carried out in equipment whose design is dominated by the requirements of the slower and temperature-specific desulfurization process. Neither process can be optimized and, in fact, the specifics of the combined reaction chemistry are unclear. Separation of the processes allows consideration of alternative combustors, sorbents, and sorption devices. The RFB desulfurizer has the potential to reduce equipment sizes through improvements in reaction rates and sorbent utilization. Additionally, separation of the combustion and sorption reactions leads to a relatively clean separation of ash and spent sorbent allowing for better waste utilization or disposal.

Advantages

Several process advantages are associated with the use of the rotating rather than the stationary fluidized bed for sulfur removal. These stem primarily from two characteristics inherent in the multi-g system. First, smaller particles can be retained in the fluidized bed, with the following three important advantages: (a) Smaller particles will contribute to higher sulfation rates because of increased surface area; the better rates will lead to a shorter gas residence time. (b) Greater sorbent utilization will occur. Sulfation causes the buildup of a product layer on the outside of the sorbent particles, which corresponds to a higher fraction of sorbent utilization in the case of a small particle than with a larger particle. (c) The low gas velocities possible in the fluidization of small particles will permit relatively long residence times. If necessary, residence times equal to those found in stationary beds may be attained. Furthermore, these residence times can be achieved without excessive pressure drop by the use of thin beds.

The second characteristic inherent in the rotating system is the reduction in the degree of elutriation. Particles leaving the inner surface of a rotating 
fluidized bed experience a net acceleration which tends to return them to the bed, thereby reducing losses through attrition. Thus, it may be anticipated that the rotating system will be better able to retain small particles than the stationary. system.

It is expected that the more compact system and reduced sorbent requirement of the RFB will lead to lower capital and operating costs.

Program Requirements

To validate the potential of the RFB it will be necessary to demonstrate increased rates of desulfurization of hot combustion product gases and better sorbent utilization as a result of its ability to utilize smaller limestone particles without a significant loss of sorbent due to elutriation. Furthermore, it wit.1 be necessary to demonstrale 1 teluced gas rcsidenco times in the sorbent bed and sufficiently low pressure loss in the bed. These requirements, if met, will result in reduced equipment sizes, better sorbent utilization, and higher sorbent throughput rates by compar1son with conventional fluid-bed combustors. To be feasible, the device will also have to be practical in the mechanical sense and able to function in the combustion gas environment.

\section{DESCRIPTION OF THE ROTATING FLUIDIZED BED}

In its simplest form, the rotating fluidized bed consists of a porous or perforated cylindrical distributor which supports a bed of sorbent particles and is rotated about its axis by a suitable drive unit. Figure 1 illustrates the general configuration of a bed. Combustion gases pass radially through the distributor from the annular space formed by a stationary cylindrical shell. The gas passes through the bed of particles which are held against the wall of the distributor by the force imposed by rotation and then travels axially, through the inner cylindrical free volume formed by the bed surface, to the outlet.

In passing through the bed, the gas flow establishes a drag force on the sorbent particle which has to balance the centrifugal force on the particle caused by its rotation about the axis of the unit. The gas velocity required to cause the particles to move from the settled bed condition to the fluid condition is called the minimum fluidization velocity. Increases above this minimum veiocity will expand the bed. At sufficiently high gas velocities, particles will be carried out of the bed by the gas stream. In the rotating system, particle trajectories can lead to recapture by the bed. A practical 1imitation on velocity. is that at which either bed expansion or particle entrainment has reached a maximum acceptable value for the partieular deoign under consideration.

The rotating system, by increasing the apparent weight of the particle, allows a significantly higher gas velocity to be used for any given particle size, in contrast to stationary beds where larger particles would be required for increased gas velocities. The smaller particles lead to a much greater surface area of sorbent for a given mass of: material and, in the case of limestone, allow greater utilization of the material at better rates before the pores of the material are blocked by the growth of calcium sulfate. 
The operation of a rotating fluidized bed at Brookhaven National Laboratory was first reported in 1960. Fluidization with force fields of up to $100 \mathrm{~g}$ was demonstrated. 1 More rigorous development and verification of the fluidization characteristics took place at BNL in the early 1970 's.2 The behavior of a rotating flutdized bed has been shown to compare favorably with the correlations developed for conventional fluidized beds. Recent investigations of the device as a combustor include work by Levy and Chen at Lehigh University, ${ }^{3}$ by $\mathrm{J}$. Swithenbank and others at the University of Sheffield in England, 4 and by J. R. Howard at the University of Aston in England. 5 A recent study at BNL dealt with the use of rotating fluid beds in filtering applications.

As conceived for the desulfurization of gases with limestone, a rotating fluidized bed would operate with a bed depth of approximately two inches, providing a satisfactorily low pressure drop and an acceptable energy requirement. It would operate at a temperature considered favorable for the 1 imestone- $\mathrm{SO}_{2}$ sorption system. The diameter of the system will be a function of the sorbent capability in terms of $\mathrm{SO}_{2}$ removal and the degree of conversion of calcium to calcium sulfate. The bed could operate either vertically or horizontally although a significant length would limit the feasibility of a horizontal approach. These design aspects are considered in the discussion of this report.

\section{EXPERIMENTAL PROCEDURE AND DESIGN}

In establishing the operating criteria for the experimental unit, a particle size range 100 to $200 \mu \mathrm{m}$ was chosen to take advantage of the higher rates at small sizes observed by others for the limestone- $\mathrm{SO}_{2}$ sorption system. An upper limit of $0.6 \mathrm{sec}$ was chosen for the residence time of the gas in the bed based on the residence time used in conventional fluidized-bed combustors. The lower limit will be determined experimenta11y. Bed depth is kept within a range of 0.5 to 2 inches in the interest of maintaining a low system pressure drop. An operating radial acceleration of up to $15 \mathrm{~g}$ has been established for hot operation. The lower limit, which depends on the extent to which the bed slumps from the wall in the vertical configuration of the distributor cylinder, was found to be approximately $100 \mathrm{rpm}$.

A cross-section view of the experimental apparatus is shown in Figure 2 . Design spertffrattons are presented in Table 1 . The bed dimensions are: 9.76 in. o.d. $\times 4.0$ in. high $\times 2.0$ in maximum radial bed thickness at minimum fluidization. Bed exit diameter was set at 3 in. Combustion of an air-propane mixture within the bed was chosen as the method for preparing high temperature combustion gases and supplying them to the rotating system. This method has the advantage of maintaining the distributor at a relatively low temperature and of requiring only the relatively simple generation of a moderately pressurized air-propane- $\mathrm{SO}_{2}$ mixture at room temperature as the feed to the RFB. Alternative methods of hot combustion gas generation include: (a) pressurized combustion prior to supply to the RFB, and (b) preparation of a pressurized room-temperature combustion-products mixture which is heated to the desired temperature prior to supply to the RFB. For the purpose of this initial study, the method selected was considered the most reasonable and expeditious.

A flow sheet of the experimental system is shown in Figure 3. A compressor supplies air at pressures of up to 100 psi. Propane and small amounts of sulfur 
dioxide are added to this air. The resulting mixture is supplied to the bed containing fluidized limestone and burned. A temperature of approximately $850^{\circ} \mathrm{C}$ is maintained in the bed. Flows of all gases are monitored by mass flow meters; flow control is manual. The gas mixture, which is sampled upstream and downstream of the fluidized bed, is lead to a sample conditioner and then to a pulsed-fluorescence analyzer to determine how quickly and how much sulfur dioxide is absorbed in the limestone bed. The hot combustion gases flow radially through the bed and exit axially from the device into a hood where they are diluted and cooled by ambient air and exhausted to the atmosphere. The details of the experimental design are discussed here. The experimental objectives are as follows:

a. To determine rates of $\mathrm{SO}_{2}$ removal from combustion gases in a benchscale atmospheric rotating fluidized bed containing a sulfur dioxide sorbent as the bed materlal.

b. To determine the extent of sorbent utilization.

c. To determine the degree of sorbent attrition.

d. To determine elutriation rates of material from the bed.

e. To use the resulting data as a basis for the selection of sorbents suitable for further study in the pilot demonstration unit.

f. To develop design information that will be useful for scale-up.

Experiment Design

A drawing of the experimental unit is shown in Figure 2. Individual components are identified. The distributor is rolled and welded into a cylinder from a sheet of multilayered fusion-bonded stainless steel screen. The distributor pressure drop is approximately $100 \%$ of the pressure drop of the fluidized bed and provides uniform fluidization over its entire area. The screen' is fitted into grooves in the top and bottom plates which provide sealing and allow for the growth of the distributor during the initial warmup of the bed.

Stainless steel-sheathed thermocouples are used to monitor the fluid-bed temperature at various depths as measured from the inside surface of the distributor. Slip rings located at the midpoint of the rotating hollow shaft transfer the thermocouple signals to the stationary support members.

The unit is belt driven by a varlable speed motor. Speed is monitored continuously by a tachometer and manually by use of a strobe light which also allows for visual monitoring of the bed surface during operation. A mechanical seal prevents leakage of the gas during operation.

The flutdizing air, which carriee the $\mathrm{SO}_{2}$ and propane components of the mixture, flows upward through the rotating hollow-shaft, passes under the distributor bottomplate, through holes in the outer edge of the plate and then through the distributor, the bed, and finally through the opening in the top plate. A hood and duct system over the unit provides dilution and cooling of the hot combustion product gas and conveys the gas to a stack for dispersal. 
INITIAL RESULTS

Process Studies

The first series of experimental runs has established and verifled operating procedures and has given an initial set of results which allow an appralsal of the operating unit and its value in the application. The results indicate sulfur removal and limestone utilization at rates which show the possibility of full-scale units within practical size limits for construction. The rate in the present device is 1 imited by the combustion product mixture flow rather than by limestone retention. Future runs will provide capability for higher gas velocities and will establish the limiting gas velocity for so breakthrough or excessive elutriation with a given particle size and tangential velocity. The initial results are shown in Table 2 .

The operating velocities range up to six times the calculated minimum fluidization velocfty. Measurement of the minimum fluidization velocity was not conclusive in these runs. In all cases, the $\mathrm{SO}_{2}$ concentration leaving the bed was low indicating better than $99 \%$ removal. The low gas residence time, when compared with the value of about 0.4 seconds for conventional beds, is clear evidence that the smaller particle size is being utilized beneficially in the rotating fluidized bed. Estimates of solids elutriation based on calculated conversion and calcining reactions and measurement of the material in the bed at the end of the run indicate losses of a few percent an hour during the experiment under operating conditions which would provide worst-case values. Plans are being made to provide for actual measurement of the particles carried out of the bed. Results should be lower.

The rate of sorption of $\mathrm{SO}_{2}$ in the bed is linear with time and follows the rate at which $\mathrm{SO}_{2}$ is introduced to bed, indicating that the 1 imiting rate for the system has not been reduced.

\section{Equipment Performance}

In general, the design of the unit has proven satisfactory for the purpose of the profect. Modification of the distributor seal design has been started however to provide more control of the experimental procedure.

In operation, leakage at the upper edge of the distributor during the cold start-up of the unit retarded the heating process and caused some loss of 1 imestone due to air streaming along the upper plate toward the discharge port. To prevent this, a flexible diaphragm was fastened to the distributor and to the upper plate making a positive seal during all stages of the operation. The results of initial runs with this new seal will be presented in the next report perioul.

Stainless steel-sheather thermocouples are used to monitor the temperatures at various points in the bed during operation. These can be used to follow the fluidization process as it develops in the bed. The couples are sufficiently sturdy that their life in the fluidized limestone is quite satisfactory. Care 
has to be taken to avold mechanical damage during sampling and probing of the bed since the sheath does become somewhat brittle during operation.

\section{DTSCUSSION AND PRELIMINARY CONCLUSIONS}

The application baseline for this feasibility study is the fluidized-bed combustor (FBC) and its design and operation as a desulfurizer. If the rotating bed design parameters matched those in most of the current FBC's where limestone desulfurtzation is applied, gas residence tmes in the bed of approximately $0.4 \mathrm{sec}$ would be necessary to insure desulfurization. A rotating fluidized bed providing this restdence time, utilizing a smaller particle, and reduced in thickness to provide a low pressure drop would be a relatively large device. Consequent1y, the appeal of the RFB will depend on the degree of improvement in the rate of sorption of $\mathrm{SO}_{2}$ and on the utilization of the limestone resulting from the bed's ability to operate with smaller particles and realize reduced gas residence times.

In a study made for BNL by the Stone \& Webster Engineering Company (SWEC) the size of a rotating fluid bed was considered in order to determine the practicality of the device. A 100-MW( $t$ ) design based on the $0.4-\mathrm{sec}$ gas residence time - with a 2-in. bed depth, 100-um particles, 0.4-fps gas velocity (twice minimum fluidization velocity), 20-g centrifugal force, and 10-atm operating pressure - resulted in a relatively large unit, $20 \mathrm{ft}$ in diameter and $100 \mathrm{ft}$ in length. On this same basis, but assuming the improved reaction rates anticipated for limestone particles based on the work of others, 6 the lower residence time requirement would raise the capacity of this same unit to a 700-MW( $t$ ) equivalent combustion produce gas rate. The gas residence time in this case is 0.06 seconds.

A second example given in the SWEC study indicates that a unit $6 \mathrm{ft}$ i.d., and $66 \mathrm{ft}$ long, handling 250- $\mu \mathrm{m}$ particles at the same operating conditions and with a $0.034-\mathrm{sec}$ residence time $(3.2-i n$. bed depth) will have the same $700-\mathrm{MW}(t)$ capacity.

Results to date confirm the ability of the RFB to obtain the better reaction rates because it can operate with smaller limestone particles. Experimental residence time as low as $0.06 \mathrm{sec}$ have been reallzed with $\mathrm{SO}_{2}$ removal exceding $99 \%$.

The removal of $\mathrm{SO}_{2}$ was limited by the rate at which it could be supplied to the experimental RFB rather than by the limestone sorption capability. The residence time can be reduced below the $0.06-\mathrm{sec}$ operating value achieved at this time. The current results vcrify that the $700-M W(t)$ unit design is achievable and that smaller units are feasible. Further experimental work will establish the limits of the limestone system in the RFB context and provide the basis for more definitive optimization studies of the applied case.

Further SWEC considerations included orientation of the unit (vertical vs horizontal), seals, solids flow, gas distribution, mechanical aspects of the rotating components, and alternative approaches to combustion gas desulfurization. They concluded that construction and operation of the RFB units are technically feasible, and that smaller units operating at higher velocities are also feasible. 
Two alternative approaches, discussed briefly, include the fixed-bed absorber and the transfer line reactor. The fixed-bed unit is dependent on solution of the support of thin beds and the feed and discharge of 1 imestone. The transfer line reactor involves recycle of the sorbent through the reactor piping system, finer particle sizes to minimize recycle, and the need to separate the gas and solids after reasonable 1 imestone conversions. Some work along these lines may be warranted as the project continues to provide a complete evaluation and comparison of the RFB concept.

\section{CONTINUING ACTIVITIES}

An improved distributor assembly design is befng fabricated and w111 allow more controllable and definable fluidization during all stages of the operation. Following installation of this distributor, a series of runs will be made to reduce the residence time to the point where the limestone sorption rate reaches its limit or until the gas velocity and g loadings are such that excessive limestone elutriation is observed.

Current1y, limestone elutriation is being measured by comparing the calculated weight of spent 1 imestone in the bed at the end of the run with the measured weight of material. Uncertainties exist because of composition changes and losses during the run, including cold start-up, and some loss during handling and sampling. Direct measurement of particle loss from the bed will be made in the future after techniques for adaptation of the necessary equipment to the rotating bed are established.

Other sorbents, and particularly the silicate cements under development at BNL, will be tested in the RFB. The difference in pore structure and behavior of other sorbents during sulfation will provide an opportunity to evaluate the RFB for a wider degree of applicability in terms of potential sorbents than limestone affords.

\section{REFERENCES}

1. L. P. Hatch, W, H. Regan, and J. R. Powell, Fluidized bed for rocket propulsion, Nucleonics, Vol: 18, No. 12, 102-3, December 1960 .

2. J. M. Henrie et al., Rotating Fluidizied Bed Reactor for Space Nuclear Propulsion, Annual Report: Design Studies and Experimental Results, June 1971June 1972, BNL 50362, September 1972.

3. E. K. Levy, N. W. Martin, and J. C. Chen, Centrifugal fluidized bed combustion, Proc. 5th Int. Conf. Fluidized Bed Combust., Vo1. III, pp.288-296, The Mitre Corporation, McLean, VA, December 1978.

4. N. Demircan, B. M. Gibbs, J. Swithenbank, and D. S. Taylor, Rotating fluidized bed combustor, Eng. Foundation Conf. on Fluidization, Cambridge University Press, 1978 .

5. C. I. Metcalfe and J. R. Howard, Fluidization and Gas Combustion in a Rotating Fluidized Bed, App1. Energy 3(1), 65-74, January 1977. 
6. R. H. Borgwardt and R. D. Harvey, Properties of carbonate rocks related to $\mathrm{SO}_{2}$ reactivity. Environ. Sci. Technol., Vo1. 6, No. 4, pp. 350-360, April ${ }^{2} 1972$.

Table 1

Bench-Scale Apparatus Design Specifications

Bed outer diameter

Bed vertfcal helght (length)

Bed mininum inner diameter

Bed exit dtameter

Bed temperature range

Bed extit pressure

Raidial acceleration range

Maximum bed thickness

Rotational speed range

Gas flow rate range

Range of equivaléint combustor eapacity

Bed and freeboard pressure-drop range
9.75 iń.

3 in.

$4.875 \mathrm{in}$.

$3.00 \mathrm{in}$.

$800^{\circ}$ to $900^{\circ} \mathrm{C}$

$1.0 \mathrm{~atm}$

0 to $15 \mathrm{~g}$

2 in.

0 to $375 \mathrm{rpm}$

25 scfm

0 th $35 \mathrm{~kW}(\mathrm{E})$

0 to $0.67 \mathrm{sec}$ 
Table 2

Experimental Results

Precalcined Greer Limestone

\begin{tabular}{|c|c|c|c|c|}
\hline \multicolumn{5}{|c|}{ Run } \\
\hline & $11 / 9$ & $12 / 14$ & $1 / 10$ & $2 / 27$ \\
\hline $\mathrm{rpm}$ & 175 & 300 & 250 & 250 \\
\hline $\mathrm{Dp}, \mathrm{um}$ & $150 \mathrm{av}$ & 195 & 210 & 210 \\
\hline Vfps & 0.74 & 0.89 & 1.15 & 1.12 \\
\hline Vmf (calc) & 0.13 & 0.33 & 0.41 & 0.41 \\
\hline $\mathrm{SO}_{2}$ in & $3500 \mathrm{ppm}$ & 3500 & 3110 & 3000 \\
\hline $\mathrm{SO}_{3}$ out & $20 \mathrm{ppm}$ & 13 & 19 & $72 \mathrm{ppm}^{\mathrm{a}}$ \\
\hline $\mathrm{Ca} / \mathrm{s}^{\mathrm{b}}$ & 2.3 & 2.5 & 2.4 & 1.8 \\
\hline$T$ residence, sec & 0.1 & 0.05 & 0.07 & 0.09 \\
\hline$\phi^{c}$ & 0.57 & 0.50 & 0.52 & 0.54 \\
\hline Bed depth; in. & 0.9 & 0.6 & 1.0 & 1.2 \\
\hline
\end{tabular}

a Sampler zero set high.

bolar ratio based on sulfated sample analysis.

CEqivalence ratio: fuel/air (actual) $\div$ fuel/air (stoichlometric). 


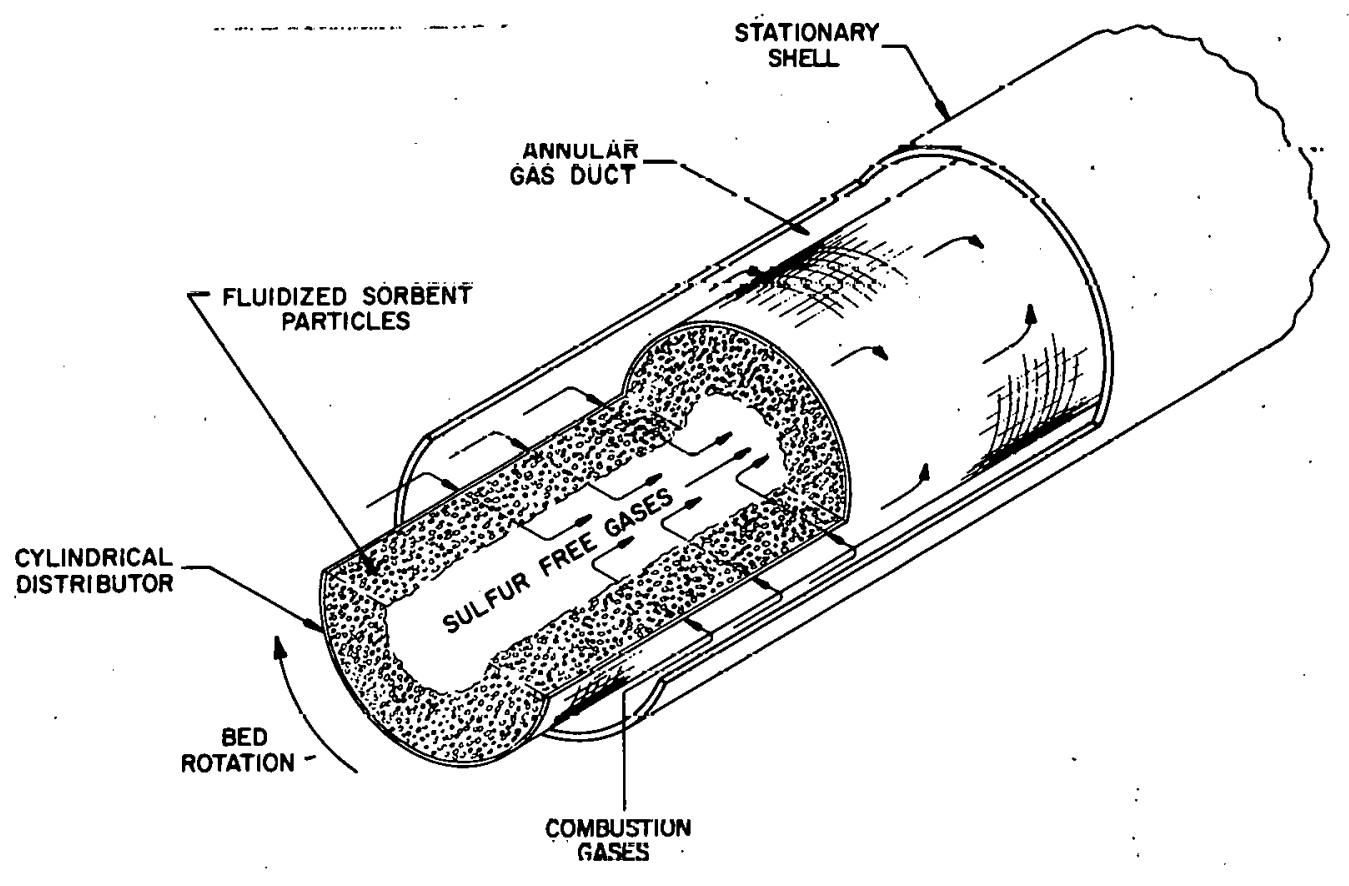

Figure 1. Rotating Fluidized Bed Desulfurizer

(Explanatory Sketch) 


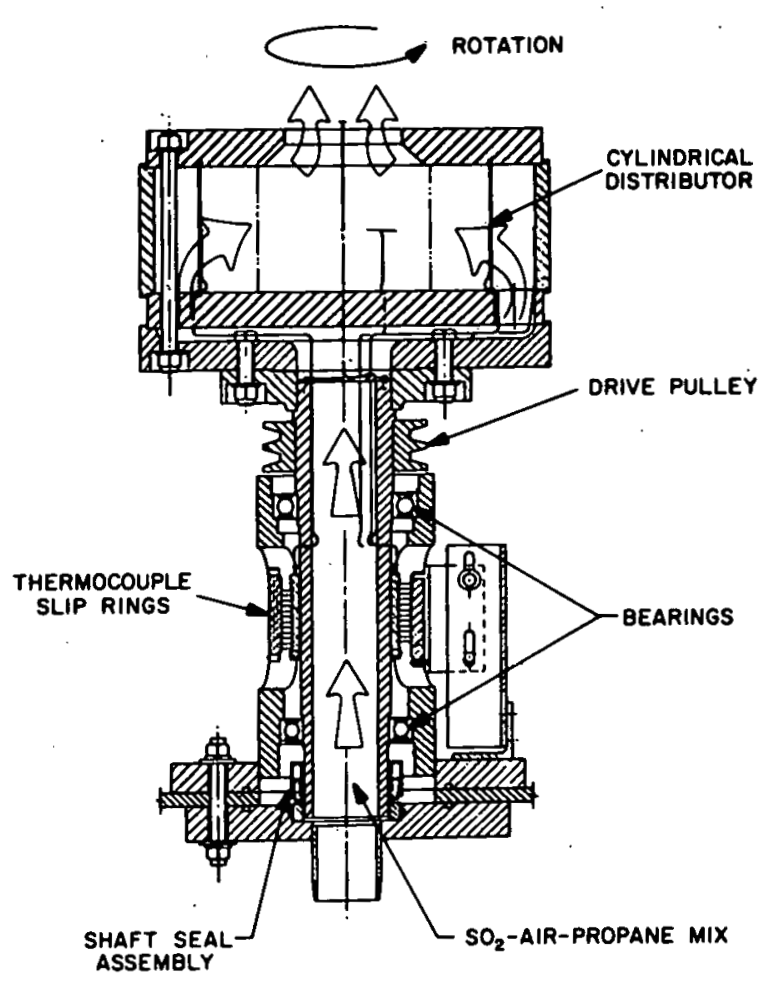

Figure 2. Experimental Rotating Fluid-Bed Assembly , 


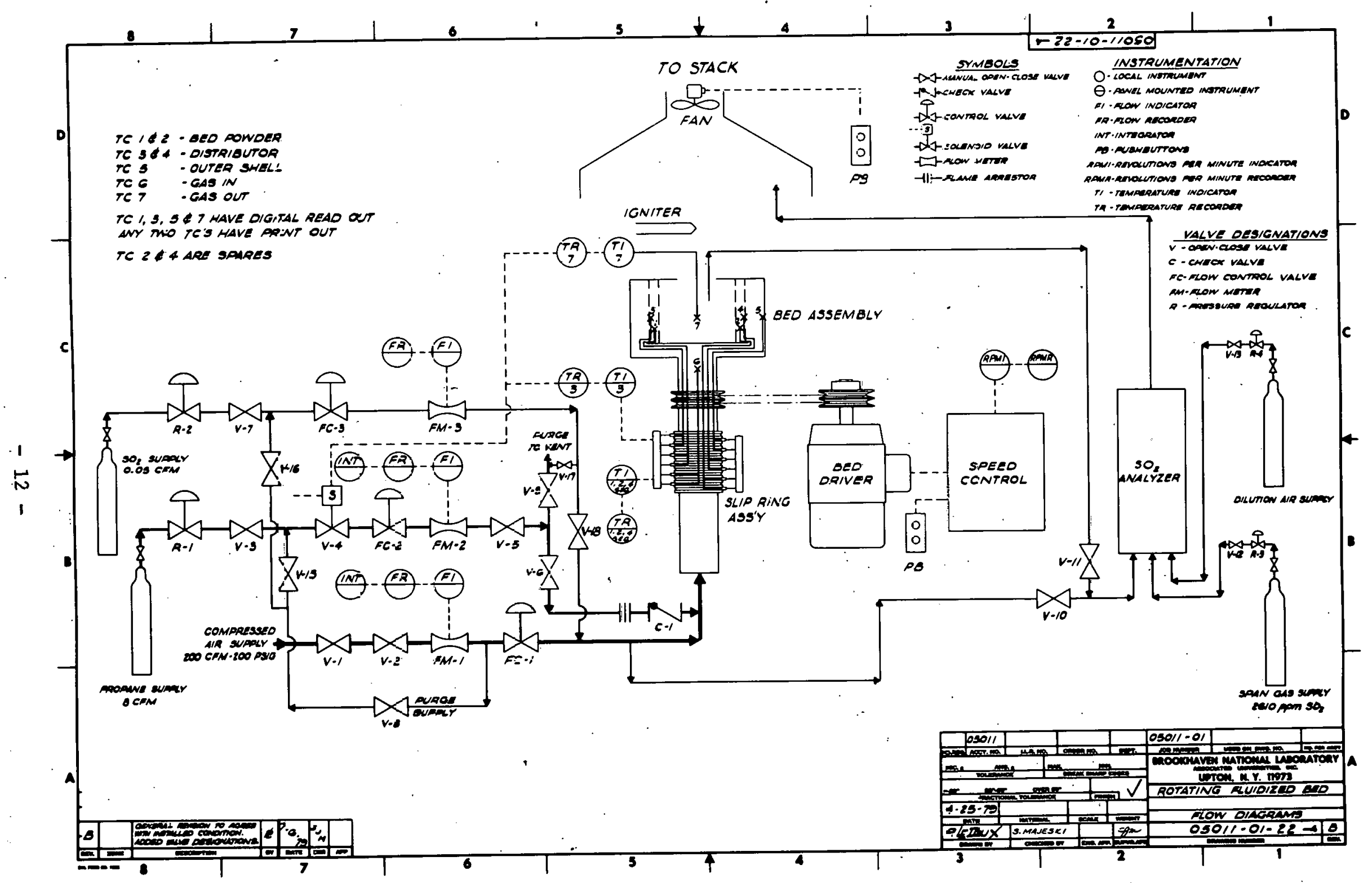

Figure 3. 